Mythen, Metaphern und Metamorphosen 
Ergebnisse der Frauenforschung

Band 45

Begründet und im Auftrag des Präsidenten der Freien Universität Berlin herausgegeben von

Prof. Anke Bennholdt-Thomsen, Germanistik

Elisabeth Böhmer, Soziologie

Prof. Marlis Dürkop, Sozialpädagogik

Prof. Ingeborg Falck, Medizin

Prof. Marion Klewitz, Geschichtsdidaktik

Prof. Jutta Limbach, Jura

Prof. Hans Oswald, Pädagogik

Prof. Renate Rott, Soziologie

Dr. Hanna Beate Schöpp-Schilling, Amerikanistik/Anglistik, Germanistik

Prof. Margarete Zimmermann, Romanistik

Koordination: Dr. Anita Runge 
Michaela Prinzinger

\section{MYTHEN, METAPHERN UND METAMORPHOSEN}

Weibliche Parodie in der zeitgenössischen griechischen Literatur

Verlag J. B. Metzler

Stuttgart . Weimar 
Die Deutsche Bibliothek - CIP-Einheitsaufnahme

Prinzinger, Michaela:

Mythen, Metaphern und Metamorphosen : weibliche Parodie in der zeitgenössischen griechischen Literatur / Michaela Prinzinger. - Stuttgart ; Weimar : Metzler, 1997

(Ergebnisse der Frauenforschung; Bd. 45)

ISBN 978-3-476-01528-0

ISBN 978-3-476-03692-6 (eBook)

DOI 10.1007/978-3-476-03692-6

NE: GT

Dieses Werk einschließlich aller seiner Teile ist urheberrechtlich geschützt. Jede Verwertung außerhalb der engen Grenzen des Urheberrechtsgesetzes ist ohne Zustimmung des Verlages unzulässig und strafbar. Das gilt insbesondere für Vervielfältigungen, Übersetzungen, Mikroverfilmungen und die Einspeicherung und Verarbeitung in elektronischen Systemen.

C 1997 Springer-Verlag GmbH Deutschland

Ursprünglich erschienen bei J. B. Metzlersche Verlagsbuchhandlung

und Carl Ernst Poeschel Verlag GmbH in Stuttgart 1997 


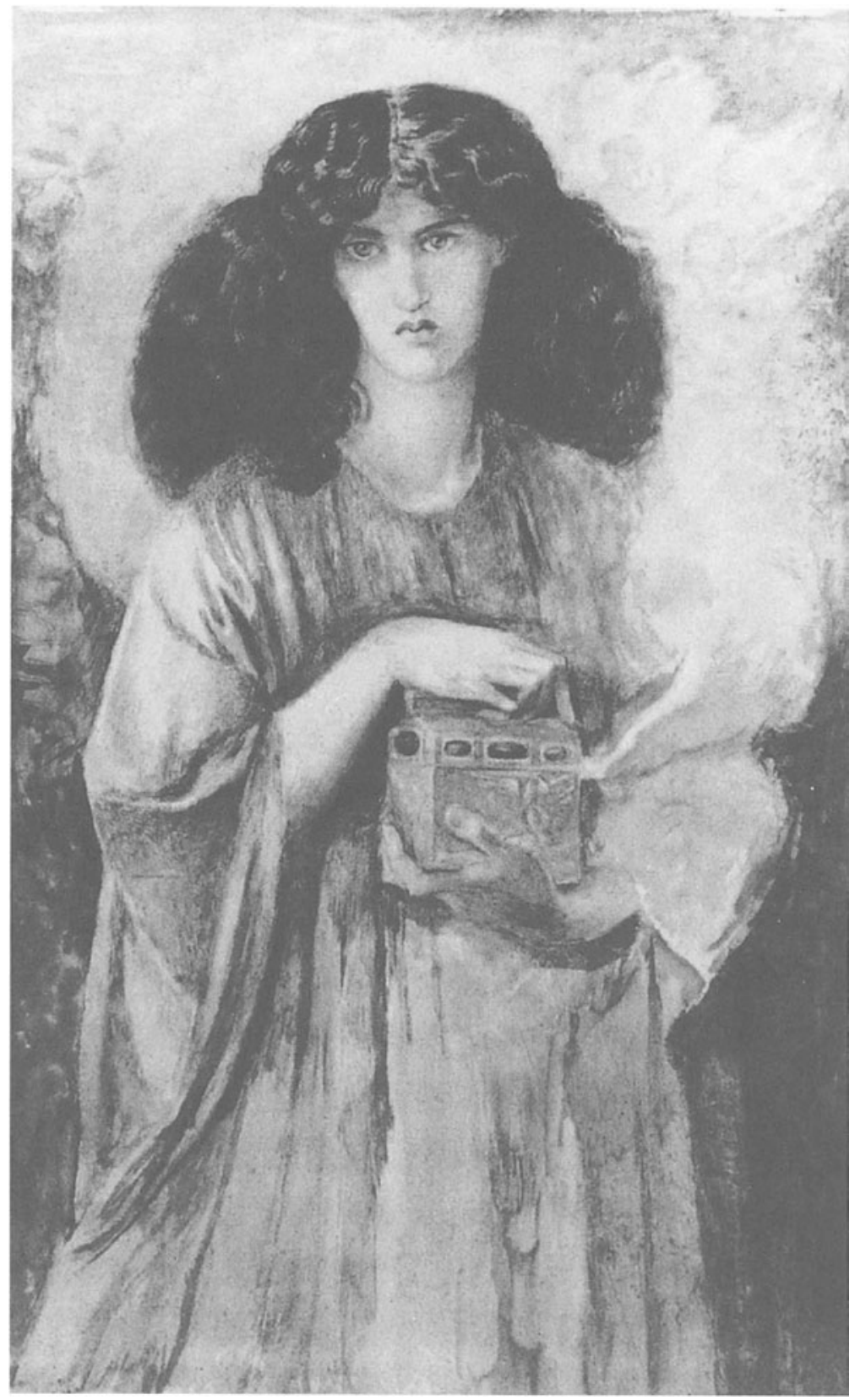

Abb. 1: Dante Gabriel Rossetti Pandora 


\section{DANKSAGUNG}

Der vorliegende Band ist die überarbeitete Fassung meiner Dissertation, die im Herbst 1995 vom Fachbereich Altertumswissenschaften der Freien Universität Berlin angenommen wurde.

An erster Stelle möchte ich Herrn Prof. Dr. D. R. Reinsch dafür danken, daß er sich bereit erklärt hat, diese Arbeit zu betreuen. Seinem aufmerksamen Interesse und großzügigen Zugeständnis von Freiräumen verdankt diese Arbeit ihr Entstehen. Meinem langjährigen Sprachlehrer M. Caramanlis möchte ich ebenfalls meinen Dank aussprechen. Griechische Freundinnen und Freunde ermöglichten mir durch ihre Gastfreundschaft eine Reihe von Aufenthalten in Athen, Thessaloniki und Ioannina. Eine große Anzahl von Kolleginnen und Kollegen an griechischen Universitäten halfen mir durch ihre Anteilnahme weiter. Das Österreichische Archäologische Institut Athen nahm mich freundlicherweise wiederholt auf. Verschiedene Sprach- und Forschungsstipendien von griechischer und österreichischer Seite sowie die Gelegenheit, als wissenschaftliche Mitarbeiterin an der Freien Universität Berlin tätig zu sein, gaben mir die Möglichkeit, mein Wissen über die griechische Kultur und Literatur zu vertiefen. Ebenfalls danken möchte ich der Zentraleinrichtung zur Förderung von Frauenstudien und Frauenforschung der Freien Universität Berlin für die Aufnahme der Arbeit in ihre Reihe „Ergebnisse der Frauenforschung“.

Mein ganz besonderer Dank gilt jedoch meinen Eltern für ihre Unterstützung und H. W. Korfmann, ohne dessen Geduld und Zuwendung ich mir diese Arbeit nicht vorstellen könnte.

\section{ANMERKUNG ZU TRANSKRIPTION UND ÜBERSETZUNG}

Eigennamen werden in einer an der Aussprache des Neugriechischen orientierten Umschrift wiedergegeben. Fast alle griechischen Textstellen und Literaturangaben werden im Ein-Akzent-System zitiert, hochsprachliche Zitate tragen sämtliche Akzente. Das Literaturverzeichnis wurde nach mechanischer Wortfolge geordnet. Die Übersetzungen stammen von der Verfasserin, wobei die Nähe zum Original Vorrang vor der Ästhetik genoß.

Berlin, 1996

Michaela Prinzinger 


\section{INHALT}

EINFÜHRUNG: Vom Vatermord zur Parodie. . . . . . . . . . . . . . . . . . 9

I. „Frauenliteratur" in Griechenland. . . . . . . . . . . . . . . . . . . 14

1. Die Ahnväter des Konzepts „Frauenliteratur“ . . . . . . . . . . . . . . . . 14

2. Literaturgeschichtsschreibung und Kanonformation . . . . . . . . . . 16

3. Die "literarische Generation" . . . . . . . . . . . . . . . 21

4. Die feministische Konzeption des literarischen Kanons. . . . . . . . . . . . 24

II. Der weibliche Diskurs seit den siebziger Jahren $\ldots \ldots \ldots$

1. Nonkonformismus und Underground . . . . . . . . . . . . . . . . 27

2. Die "Generation der siebziger Jahre“ . . . . . . . . . . . . . . . . . 38

3. Die „Politisierung“ der zeitgenössischen Erzählliteratur. . . . . . . . . . 45

4. Die Inszenierung eines weiblichen Gegendiskurses . . . . . . . . . . . 55

III. Parodie als Auseinandersetzung mit der kulturellen Tradition . . . 73

1. Rea Galanaki : Reflexionen über das literarische Subjekt . . . . . . . . . . . 74

a. Die Büchse der Pandora . . . . . . . . . . . . . . . . . 74

b. Die Umwandlung von Bildvorlagen . . . . . . . . . . . . . . . . . . 78

c. Die Wende zur Romantik . . . . . . . . . . . . . . . . . . . . . . . 97

d. Die Kopie historischer Folien. . . . . . . . . . . . . . . . . . 103

2. Alexandra Deligiorgi: Die Durchquerung des kulturellen Imaginären . . . 109

a. Der lahme Pegasus . . . . . . . . . . . . . . . . . . . . . . . . . . . . . . . . . . . . . . .

b. Die Entdeckung des Mütterlichen . . . . . . . . . . . . . . . . . 117

c. Eigenes Zimmer, eigenes Auto, eigenes Leben . . . . . . . . . . . . 124

d. Die andere Hälfte . . . . . . . . . . . . . . . . . . . . . . . 135

3. Margarita Karapanu: Mythische Re-Visionen in karnevalesker Verkleidung. . 147

a. Das Unheimliche. . . . . . . . . . . . . . . . . . . 147

b. Das Unsinnige . . . . . . . . . . . . . . . . . . . . . . . . . . . . . 159

c. Die Welt der Nymphen. . . . . . . . . . . . . . . . . . . . 168

d. Weibliches Schreiben als Travestie . . . . . . . . . . . . . . 175

Schlusswort: Parodie als Fälschung . . . . . . . . . . . . . . . . . 182 
Anmerkungen. . . . . . . . . . . . . . . . . . . . . 189

Literaturverzeichnis . . . . . . . . . . . . . . . . . . 237

Abbildungsverzeichnis. . . . . . . . . . . . . . . . . 252 